\title{
Lung cancer survival in England: trends in non-small-cell lung cancer survival over the duration of the National Lung Cancer Audit
}

\author{
A Khakwani ${ }^{*}, 1$, A L Rich ${ }^{2}$, H A Powell ${ }^{1,3}$, L J Tata ${ }^{1}$, R A Stanley ${ }^{4}$, D R Baldwin ${ }^{2}$, J P Duffy ${ }^{5}$ and R B Hubbard ${ }^{1,3}$ \\ ${ }^{1}$ Division of Epidemiology and Public Health, University of Nottingham, Nottingham NG5 1PB, UK; ${ }^{2}$ Department of Respiratory \\ Medicine, Nottingham University Hospitals, City campus, Hucknall Road, Nottingham NG5 1PB, UK; ${ }^{3}$ Nottingham Respiratory \\ Research Unit, University of Nottingham, Nottingham NG5 1PB, UK; ${ }^{4}$ Clinical Audit Support Unit, Health and Social Care \\ Information Centre, Leeds LS1 6AE, UK and ${ }^{5}$ Department of Thoracic Surgery, Nottingham University Hospitals, City campus, \\ Hucknall Road, Nottingham NG5 1PB, UK
}

Background: In comparison with other European and North American countries, England has poor survival figures for lung cancer. Our aim was to evaluate the changes in survival since the introduction of the National Lung Cancer Audit (NLCA).

Methods: We used data from the NLCA to identify people with non-small-cell lung cancer (NSCLC) and stratified people according to their performance status (PS) and clinical stage. Using Cox regression, we calculated hazard ratios (HRs) for death according to the year of diagnosis from 2004/2005 to 2010; adjusted for patient features including age, sex and co-morbidity. We also assessed whether any changes in survival were explained by the changes in surgical resection rates or histological subtype.

Results: In this cohort of 120745 patients, the overall median survival did not change; but there was a $1 \%$ annual improvement in survival over the study period (adjusted HR 0.99, 95\% confidence interval (Cl) 0.98-0.99). Survival improvement was only seen in patients with good PS and early stage (adjusted HR 0.97, 95\% $\mathrm{Cl} 0.95-0.99$ ) and this was partly accounted for by changes in resection rates.

Conclusion: Survival has only improved for a limited group of people with NSCLC and increasing surgical resection rates appeared to explain some of this improvement.

Overall survival is an important index to consider when evaluating the effectiveness of cancer management. Compared with other European and North American countries, England has poor overall survival for lung cancer (Coleman et al, 2011; Woolhouse, 2011). This may be partly due to differences in cancer management, such as lower surgical resection rates (Riaz et al, 2012b), but patient and tumour features may also influence survival, and studies have found that in the UK patients tend to present later with more advanced disease and more co-morbid illness (Imperatori et al, 2006).

The National Lung Cancer Audit (NLCA) commissioned by the Healthcare Quality Improvement Partnership was established in 2004 to measure the quality of services for patients with lung cancer provided by the National Health Service (NHS) in order to improve outcomes (Rich et al, 2011b). The audit has been used to suggest standards, which NHS trusts can use to monitor and understand their own practice. These include an overall histological confirmation rate of $75 \%$, having $80 \%$ patients seen by a lung cancer nurse specialist and 95\% patients being discussed by a multi-disciplinary team (MDT).

Recent reports by the Office of National Statistics (ONS) suggest that both 1-year and 5-year lung cancer survival have improved in the UK since 1996 (ONS, 13 December 2011), but only by a small margin. Until the establishment of the NLCA in 2004, there were no data that could be used to calculate according to stage and 
fitness in the UK. Given the heterogeneity of patients with lung cancer, it seems unlikely that improvements will be the same for the cohort as a whole. It may be that changes in survival occur only in some groups depending on their socio-demographic (e.g. age, sex and ethnicity) and clinical features (e.g. stage, performance status (PS) and co-morbidity).

In this study, we used data from the NLCA database from 2004 to 2010 to assess whether there has been a temporal change in the overall survival. We subdivided the cohort based on the patient features most strongly associated with survival. We also assessed whether any of the survival difference was explained by increasing surgical resection rates.

\section{MATERIALS AND METHODS}

We used data on all patients in the NLCA who were first seen in England between 1 January 2004 and 31 December 2010 and had proven or presumed non-small-cell lung cancer (NSCLC). We restricted our analyses to NSCLC only and excluded all patients with small-cell lung cancer, mesothelioma or carcinoid because their pathology, treatment and survival time varies greatly. The NLCA database is a longitudinal database consisting of anonymous, computerised records of individuals with a diagnosis of primary lung cancer. The NLCA has collected data on demographics, tumour features and treatment since 2004 via the 157 English NHS trusts responsible for managing patients with lung cancer. The database currently holds records for over 223000 individuals, with $\sim 39000$ added in 2010. Results are reported annually at the level of an individual NHS trust.

In line with methods used by the NLCA to define lung cancer type, we identified cases of pathologically confirmed 'non-smallcell lung cancer' based on the recorded Systematised Nomenclature of Medicine (SNOMED) codes in the database. In addition, all cases for which the SNOMED code was missing, or was coded as 'unknown lung cancer', were classified as 'non-small-cell lung cancer'; this is in line with the standard NLCA definition of NSCLC (NHSIC, 2010; 2011). Histological subtype was similarly identified using the SNOMED codes.

Covariates. Age at diagnosis, sex and the source of referral to the MDT were identified from the NLCA database. Performance status was classified according to the World Health Organisation definition and the stage of disease was defined using the Union International Contre le Cancer definition (versions 6 and 7).

Although the NLCA collects data on co-morbidity, these data are often incomplete and do not cover the whole spectrum of comorbidities. Therefore, we obtained permission to link the NLCA with the Hospital Episode Statistics (HES) data set to calculate a composite score of co-morbidity: the Charlson co-morbidity Index. The HES data were also used for information on ethnicity and to identify patients with Office of Population Censuses and Survey Classification of Intervention (OPCS-4) codes for procedures consistent with potentially curative surgery for lung cancer as has been previously described (Powell et al, 2013). Procedure data were only available until the end of 2009.

Survival. To determine survival, we created a start date using the recorded date of diagnosis. In the absence of a date of diagnosis, a pseudo start date was generated using the median day difference between date of diagnosis, for the whole cohort, and the following dates in this order: (1) date first seen, (2) date of referral or (3) date discussed by MDT. These median differences were then added or subtracted from the date field available for those individuals who did not have a date of diagnosis. Patients for whom a start date could not be generated were excluded.

We divided the cohort into year bands (from 2004 to 2010) using the start date described above. Patients diagnosed with lung cancer in 2004 and 2005 were grouped together to create a comparator group of adequate size. All other years were analysed individually.

An end date for each patient was created using either the date of death (provided by ONS) or the date of the last ONS cross-check for death dates (31 December 2011).

Statistical analysis. All data management and statistical analyses were performed using Stata version 12 (StataCorp, College Station, TX, USA). Initially we calculated the median survival (in days) for our whole cohort and then separately by grouping patients according to their year of diagnosis. In order to quantify the factors which were associated with survival and to determine whether there was any change in survival over time, we performed a series of univariate and multivariate Cox regression analyses to calculate hazard ratios (HRs) for death for patients diagnosed in each year, adjusting for all the patient features outlined above.

We then stratified our cohort based on the two factors we identified as being most strongly associated with survival in our multivariate analysis (factors which are also clinically relevant for the management of lung cancer as identified in the National Institute for Heath and Clinical Excellence (NICE) guidelines) (NICE, April 2011). We repeated the Cox regression analyses on the stratified groups. In addition to adjusting for patient and tumour features in this analysis, we adjusted for surgical resection and histological subtype (adenocarcinoma or squamous cell carcinoma) to see if these accounted for any changes in survival over time. We also calculated the HRs to see whether the beneficial effect of surgery is maintained over the years in any group where the surgical resection rate was increasing.

\section{RESULTS}

There were a total of 121915 individuals with proven or presumed NSCLC in the NLCA. The $1170(0.95 \%)$ patients for whom a start date could not be generated were excluded from further analyses and therefore our analyses were based on 120745 patients with NSCLC diagnosed between 1 January 2004 and 31 December 2010. The median age at diagnosis was 72 years (IQR 64-79); $58 \%$ $(n=69379)$ of the patients were male, $32 \%(n=38546)$ had stage IV disease and $36 \%(n=44118)$ were with a PS of 0 or 1 . The overall median survival of patients with NSCLC remained fairly static over the duration of the NLCA (Table 1).

The results of our univariate and multivariate Cox regression analyses showed that the overall survival has improved by $1 \%$ annually over the duration of the audit (adjusted HR 0.99, 95\% confidence interval $(\mathrm{CI})=0.98-0.99)$. Men had worse survival than

\begin{tabular}{|c|c|c|c|c|}
\hline Years & $\begin{array}{l}\text { Number of } \\
\text { patients } \\
\text { reported }\end{array}$ & $\begin{array}{l}\text { Median } \\
\text { survival } \\
\text { in days }\end{array}$ & $\begin{array}{l}\text { IOR in } \\
\text { days }\end{array}$ & $\begin{array}{c}\text { Number of } \\
\text { patients surviving } \\
>1 \text { year }(\%)\end{array}$ \\
\hline Whole cohort & 120745 & 189 & $58-547$ & 40921 (33.89) \\
\hline $2004 / 2005$ & 15267 & 193 & $61-558$ & $5271(34.53)$ \\
\hline 2006 & 15252 & 193 & $60-544$ & $5306(34.18)$ \\
\hline 2007 & 18193 & 189 & $58-533$ & $6110(33.58)$ \\
\hline 2008 & 21860 & 182 & $56-522$ & 7240 (33.12) \\
\hline 2009 & 25072 & 186 & $57-546$ & 8559 (34.14) \\
\hline 2010 & 24828 & 182 & $55-585$ & 8435 (33.97) \\
\hline
\end{tabular}


women (adjusted HR 1.13, 95\% CI 1.12-1.14) and as age, stage, PS and co-morbidity index increased, survival worsened (Table 2). The adjusted HR for patients with a PS of 4 was 4.58 (95\% CI $4.45-$ 4.71) compared with those patients with a PS of 0 . Patients who were initially admitted as an emergency before being diagnosed with lung cancer or who had been initially referred from a nonrespiratory consultant or following $\mathrm{A} \& \mathrm{E}$ attendance also showed a poorer prognosis compared with patients referred by a GP (adjusted HR 1.53, 1.05 and 1.44, respectively).

Stratification by clinical features. Based on our multivariate analyses, PS and stage were strongly associated with survival. As these two features are also clinically relevant and used by MDTs to determine the management of patients, we stratified our cohort according to these variables and made a separate group for patients with either missing PS or missing stage $(n=54312)$. We excluded $1145(0.9 \%)$ patients who had a code for surgery more than three months before or six months after the date of diagnosis to exclude any patients who might have had thoracic surgery not related to lung cancer. Our stratification was therefore based on 119600 patients. Based on the similarity of the clinical management of the patients (as recommended by NICE guidelines), (NICE, April 2011) we created five groups as outlined in Table 3 . The results in Table 3 demonstrate that having adjusted for several patient features, including age, sex, ethnicity, co-morbidity and source of referral, the overall survival for patients in group 1 improved from 2004/2005 to 2010 (adjusted HR 0.74 in 2010, 95\% CI 0.67-0.81), whereas the overall survival for patients in groups 4 and 5 (patients with poor PS and advanced stage) remained essentially stable (Figure 1). There was also a slight improvement seen in group 3 ( $P$-value for trend 0.03$)$.

Surgical resection. As the data for procedures were only available up to 2009, we have not adjusted for surgery for patients diagnosed in 2010. Surgical resection rates for NSCLC increased from $12 \%$ in $2004 / 2005$ to $14.2 \%$ in 2009 . There was an increase in the proportion of surgical procedures that were bi-lobectomies (3\% in $2004 / 2005$ to $4 \%$ in 2009 ) and lobectomies (61\% in $2004 / 2005$ to $68 \%$ in 2009), whereas the proportion of pneumonectomies decreased $(11 \%$ in $2004 / 2005$ to $8.7 \%$ in 2009). As well as adjusting our stratified groups for patient features, we adjusted for evidence of surgical resection in groups 1-3. Patients in groups 4 and 5 are unlikely to have curative surgery and were excluded from this analysis. The largest absolute increase in resection rates was seen in group 1 (50\% in 2006 to $57 \%$ in 2009$)$ and in group $2(13 \%$ in 2006 to $18 \%$ in 2009), whereas resection rates in group 3 remained stable (5\%) (Supplementary Figure 1).

Table 3 also illustrates the results of multivariate Cox regression analysis including surgery along with all other variables. The major annual survival advantage was seen in group 1 (annual HR 0.97, $95 \%$ CI $0.95-0.99)$. Some of this survival advantage was accounted for when we adjusted for surgical intervention. Surgery accounted for all of the annual survival advantage in group 2 .

Table 4 illustrates the benefit of surgery in groups 1 and 2 compared with patients who did not undergo surgical resection in the same groups over the lifetime of the NLCA. Patients who received surgery had better prognosis compared with patients in the same group who did not have surgery (adjusted HR 0.30 in 2005 and adjusted HR 0.31 in 2009 for group 1), even though the resection rate has increased every year since 2006 .

Histological subtype. To assess the influence of histological subtype on survival, we performed survival analyses restricted to patients with adenocarcinoma or squamous cell carcinoma identified by pre- or post-operative histology and a recorded stage. This analysis was based on 28997 patients, who accounted for $24 \%$ of our stratified population (14160 adenocarcinomas and 14837 squamous cell carcinomas). Table 5 shows that the proportion of patients with adenocarcinoma increased over time, especially in groups 1 and 4. Cox regression revealed that adjusting for histological subtype along with patient features did not change/ affect the HRs in any of the patient subgroups.

\section{DISCUSSION}

Survival in lung cancer is poor and understanding whether it has changed since the NLCA was initiated in 2004 and the factors which influence it may provide important information to improve standards of care in England. Using data from the NLCA, we conclude that the overall survival of patients with NSCLC has improved very slightly over the duration of the NLCA, with a $1 \%$ increase in overall survival year on year. By grouping patients based on the two most important factors determining survival (i.e. PS and stage), we observed that the survival of patients with early stage cancer and good PS has improved over the duration of the NLCA by $3 \%$ annually, which might seem small, but it corresponds to an improvement of $29 \%$ per 5 -year period. However, there has been no change in the overall survival of patients with advanced disease and poor PS since 2004/2005.

Surgical resection rates have risen slowly but steadily throughout the duration of the NLCA and this accounted for much of the improvement in survival seen in groups 1 and 2 . The beneficial association of surgery on survival has, however, remained the same indicating that there may be room to increase resection rates further before harm outweighs the benefits. The proportion of patients with adenocarcinoma is going up over time but there was no evidence that patients with adenocarcinoma had better survival compared with those with squamous cell carcinoma.

Strengths and limitations. The main strengths of our study are the large sample size and the representative nature of the cases included. Although data entry into the NLCA database is nonmandatory, the data set has been validated in previous studies and found to be representative of individuals with lung cancer in England (Rich et al, 2011b). Unlike some of the international studies which used cancer registry data (which do not have information on the PS, co-morbidity, etc.) and in which case-mix adjustment is not possible (Coleman et al, 2008; Woolhouse, 2011), our results are likely to demonstrate the real change in survival for patients in England. We have used a valid measure of comorbidity, the Charlson Index using the HES database which has shown coding accuracy of $91 \%$ for diagnostic International Classification of Diseases codes (Campbell et al, 2001). The potential selection bias of choosing patients who generally have a better prognosis and the importance of case-mix adjustment was highlighted in a study comparing survival in Varese (Italy) and Teesside (UK) (Imperatori et al, 2006), which found that Teesside had worse lung cancer survival mainly because of the different patient demographics (older age, later stage and more comorbidities) compared with Varese.

Although the case ascertainment for NLCA has improved and the number of records with missing data have declined since the database began in 2004 (NHSIC, 2010; 2011), the main weakness of this study still remains in the missing data. The variables with the greatest proportion of missing data were PS and stage with almost $45 \%$ of our initial cohort having missing data on either PS or stage; this has, however, improved over time. Patients with good PS and missing stage or vice versa did show an improvement in survival similar to group 1, although survival for other subgroups of patients with missing data did not really change (Supplementary Table 1). This suggests that the missing data are likely to be random rather than any systematic reason for incomplete data entry. We also carried out a sensitivity survival analysis $(n=89953)$ excluding all patients in the audit from 2004 to 


\section{Table 2. Result of Cox regression analysis for patients' features in those with NSCLC ( $n=120745)$}

\begin{tabular}{|c|c|c|c|c|c|}
\hline & No. of patients (\%) & $\begin{array}{c}\text { No. of patients who } \\
\text { died (\%) }\end{array}$ & $\begin{array}{l}\text { Unadjusted } \\
\text { HR }(95 \% \mathrm{Cl})\end{array}$ & $\begin{array}{l}\text { Adjusted } \mathrm{HR}^{\mathrm{a}} \\
(95 \% \mathrm{Cl})\end{array}$ & $\boldsymbol{P}$-value \\
\hline \multicolumn{6}{|l|}{ Year } \\
\hline $\begin{array}{l}2004 / 2005 \\
2006 \\
2007 \\
2008 \\
2009 \\
2010\end{array}$ & $\begin{array}{l}15267(12.64) \\
15525(12.86) \\
18193(15.07) \\
21860(18.10) \\
25072(20.76) \\
24828(20.56)\end{array}$ & $\begin{array}{l}13960(91.44) \\
14051(90.51) \\
16333(89.78) \\
19103(87.39) \\
20667(82.43) \\
18090(72.86)\end{array}$ & $\begin{array}{c}1 \\
1.00(0.98-1.03) \\
1.03(1.00-1.05) \\
1.03(1.01-1.05) \\
1.00(0.98-1.02) \\
0.99(0.97-1.02)\end{array}$ & $\begin{array}{c}1 \\
1.02(0.99-1.04) \\
1.02(1.00-1.04) \\
0.99(0.97-1.01) \\
0.95(0.93-0.97) \\
0.98(0.96-1.00)\end{array}$ & $<0.001^{\mathrm{b}}$ \\
\hline \multicolumn{6}{|l|}{ Sex } \\
\hline $\begin{array}{l}\text { Female } \\
\text { Male }\end{array}$ & $\begin{array}{l}51366(42.54) \\
69379(57.46)\end{array}$ & $\begin{array}{l}42476(82.69) \\
59728(86.09)\end{array}$ & $\begin{array}{c}1 \\
1.10(1.09-1.12)\end{array}$ & $\begin{array}{c}1 \\
1.13(1.12-1.14)\end{array}$ & $<0.001$ \\
\hline \multicolumn{6}{|l|}{ Age } \\
\hline $\begin{array}{l}<54 \\
55-59 \\
60-64 \\
65-69 \\
70-74 \\
75-79 \\
80-84 \\
85+\end{array}$ & $\begin{array}{c}8097(6.71) \\
8672(7.18) \\
14342(11.88) \\
17846(14.78) \\
20715(17.16) \\
21897(18.13) \\
17375(14.39) \\
11801(9.77)\end{array}$ & $\begin{array}{c}6111(75.47) \\
6935(79.97) \\
11475(80.01) \\
14511(81.31) \\
17462(84.30) \\
19087(87.17) \\
15658(90.12) \\
10965(92.92)\end{array}$ & $\begin{array}{c}1 \\
1.12(1.08-1.16) \\
1.15(1.12-1.19) \\
1.22(1.18-1.25) \\
1.35(1.31-1.39) \\
1.51(1.47-1.55) \\
1.73(1.68-1.79) \\
2.05(1.99-2.11)\end{array}$ & $\begin{array}{c}1 \\
1.12(1.09-1.16) \\
1.19(1.16-1.23) \\
1.25(1.21-1.29) \\
1.35(1.31-1.39) \\
1.45(1.40-1.49) \\
1.55(1.51-1.60) \\
1.62(1.57-1.68)\end{array}$ & $<0.001^{b}$ \\
\hline \multicolumn{6}{|l|}{ Stage } \\
\hline $\begin{array}{l}\text { IA-IB } \\
\text { IIA-IIB } \\
\text { IIIA } \\
\text { IIIB } \\
\text { IV } \\
\text { Missing }\end{array}$ & $\begin{array}{c}12156(10.07) \\
5836(4.83) \\
8789(7.28) \\
14209(11.77) \\
38546(31.92) \\
41209(34.13)\end{array}$ & $\begin{array}{c}6045(49.73) \\
3751(64.27) \\
7042(80.12) \\
12754(89.76) \\
36600(94.95) \\
36012(87.39)\end{array}$ & $\begin{array}{c}1 \\
1.54(1.48-1.60) \\
2.35(2.27-2.43) \\
3.30(3.20-3.40) \\
5.27(5.13-5.42) \\
3.11(3.03-3.20)\end{array}$ & $\begin{array}{c}1 \\
1.54(1.48-1.61) \\
2.33(2.25-2.42) \\
3.20(3.10-3.30) \\
4.58(4.45-4.71) \\
2.78(2.70-2.86)\end{array}$ & $<0.001^{b}$ \\
\hline \multicolumn{6}{|l|}{ Performance status } \\
\hline $\begin{array}{l}0 \\
1 \\
2 \\
3 \\
4 \\
\text { Missing }\end{array}$ & $\begin{array}{c}16984(14.07) \\
27134(22.47) \\
17963(14.88) \\
16051(13.29) \\
5320(4.41) \\
37293(30.89)\end{array}$ & $\begin{array}{c}11395(67.09) \\
21775(80.25) \\
16378(91.18) \\
15462(96.33) \\
5228(98.27) \\
31966(85.72)\end{array}$ & $\begin{array}{c}1 \\
1.49(1.45-1.52) \\
2.43(2.38-2.49) \\
4.01(3.92-4.11) \\
7.24(7.00-7.48) \\
1.83(1.79-1.87)\end{array}$ & $\begin{array}{c}1 \\
1.28(1.25-1.31) \\
1.84(1.80-1.89) \\
2.72(2.65-2.79) \\
4.39(4.24-4.54) \\
1.55(1.52-1.59)\end{array}$ & $<0.001^{\mathrm{b}}$ \\
\hline \multicolumn{6}{|l|}{ Ethnicity } \\
\hline $\begin{array}{l}\text { White } \\
\text { Black } \\
\text { Asian } \\
\text { Mixed } \\
\text { Other } \\
\text { Missing }\end{array}$ & $\begin{array}{c}90367(74.84) \\
872(0.72) \\
1182(0.98) \\
178(0.15) \\
673(0.56) \\
27473(22.75)\end{array}$ & $\begin{array}{c}76992(85.20) \\
688(78.90) \\
892(75.47) \\
142(79.78) \\
537(79.79) \\
22953(83.55)\end{array}$ & $\begin{array}{c}1 \\
0.81(0.75-0.88) \\
0.72(0.68-0.77) \\
0.83(0.71-0.98) \\
0.86(0.79-0.93) \\
1.06(1.05-1.08)\end{array}$ & $\begin{array}{c}1 \\
0.80(0.74-0.87) \\
0.68(0.63-0.73) \\
0.88(0.74-1.04) \\
0.80(0.73-0.87) \\
1.08(1.06-1.10)\end{array}$ & $<0.001^{\mathrm{c}}$ \\
\hline \multicolumn{6}{|l|}{ Charlson index } \\
\hline $\begin{array}{l}0 \\
1 \\
2 \& 3 \\
4+\end{array}$ & $\begin{array}{l}47870(39.65) \\
23992(19.87) \\
20319(16.83) \\
28564(23.66)\end{array}$ & $\begin{array}{l}38513(80.45) \\
19806(82.55) \\
17046(83.89) \\
26839(93.96)\end{array}$ & $\begin{array}{c}1 \\
1.06(1.05-1.08) \\
1.14(1.12-1.16) \\
2.03(2.00-2.06)\end{array}$ & $\begin{array}{c}1 \\
1.00(0.99-1.02) \\
1.01(0.99-1.03) \\
1.53(1.50-1.55)\end{array}$ & $<0.001^{b}$ \\
\hline \multicolumn{6}{|l|}{ Source of referral } \\
\hline $\begin{array}{l}\text { Referral from GP } \\
\text { Emergency admission } \\
\text { Domiciliary visit } \\
\text { Ref. from consultant } \\
\text { Self-referral } \\
\text { Other (private health care) } \\
\text { Following A\&E attendance } \\
\text { General dental practice } \\
\text { Community dental service } \\
\text { Not known }\end{array}$ & $\begin{array}{r}57864(47.92) \\
15399(12.75) \\
319(0.26) \\
23385(19.37) \\
174(0.14) \\
8289(6.86) \\
7340(6.08) \\
45(0.04) \\
8(0.01) \\
7922(6.56)\end{array}$ & $\begin{array}{c}47234(81.63) \\
14557(94.53) \\
256(80.25) \\
19476(83.28) \\
146(83.91) \\
6877(82.97) \\
6759(92.08) \\
44(97.78) \\
6(75.00) \\
6849(86.46)\end{array}$ & $\begin{array}{c}1 \\
2.19(2.15-2.23) \\
0.96(0.85-1.09) \\
1.16(1.14-1.18) \\
1.11(0.94-1.30) \\
1.08(1.05-1.10) \\
1.94(1.89-1.99) \\
1.65(1.23-2.22) \\
1.00(0.45-2.23) \\
1.15(1.12-1.18)\end{array}$ & $\begin{array}{c}1 \\
1.53(1.50-1.56) \\
0.97(0.86-1.10) \\
1.05(1.03-1.06) \\
0.98(0.83-1.15) \\
0.99(0.97-1.02) \\
1.44(1.40-1.48) \\
1.46(1.09-1.96) \\
0.99(0.44-2.20) \\
1.07(1.04-1.09)\end{array}$ & $<0.001^{c}$ \\
\hline $\begin{array}{l}\text { Abbreviations: } \mathrm{Cl}=\text { confidence } \\
\text { a }_{\text {HR }} \text { adjusted for all other vari } \\
\text { b }_{P \text {-value for trends. }} \\
{ }^{{ }_{\text {L }} \text {-og-likelihood ratio test. }}\end{array}$ & $\begin{array}{l}\text {; HR = hazard ratio. } \\
\text { the table. }\end{array}$ & & & & \\
\hline
\end{tabular}




\begin{tabular}{|c|c|c|c|c|c|c|}
\hline Years & $\begin{array}{l}\text { Number of } \\
\text { patients (n) }\end{array}$ & $\begin{array}{c}\text { Proportions of } \\
\text { patients (\%) }\end{array}$ & $\mathrm{HR}(95 \% \mathrm{Cl})^{\mathrm{a}}$ & $\begin{array}{c}\text { Annual } \\
\text { HR }(95 \% \mathrm{Cl})^{\mathrm{a}}\end{array}$ & $\operatorname{HR}(95 \% \mathrm{Cl})^{\mathrm{b}}$ & $\begin{array}{c}\text { Annual } \\
\mathrm{HR}(95 \% \mathrm{Cl})^{\mathrm{b}}\end{array}$ \\
\hline \multicolumn{7}{|c|}{ Whole cohort } \\
\hline $2004-2010$ & 119600 & 100 & $0.99(0.98-0.99)$ & & $0.99(0.98-0.99)$ & \\
\hline \multicolumn{7}{|c|}{ Group $1=$ PS $0 / 1 / 2$ and stage IA-IIB } \\
\hline $\begin{array}{l}2004 / 2005 \\
2006 \\
2007 \\
2008 \\
2009 \\
2010\end{array}$ & $\begin{array}{l}1098 \\
1206 \\
1567 \\
2038 \\
3166 \\
3545\end{array}$ & $\begin{array}{r}7.2 \\
7.8 \\
8.7 \\
9.4 \\
12.7 \\
14.4\end{array}$ & $\begin{array}{c}1 \\
0.98(0.89-1.08) \\
0.90(0.82-0.99) \\
0.85(0.77-0.93) \\
0.75(0.68-0.82) \\
0.74(0.67-0.81)\end{array}$ & $0.97(0.95-0.99)$ & $\begin{array}{c}1 \\
0.98(0.89-1.09) \\
0.94(0.85-1.03) \\
0.91(0.83-1.00) \\
0.82(0.75-0.90)\end{array}$ & $0.99(0.97-1.00)$ \\
\hline
\end{tabular}

\begin{tabular}{|c|c|c|c|c|c|c|}
\hline $2004 / 2005$ & 496 & 3.2 & 1 & & 1 & \\
\hline 2006 & 609 & 3.9 & $1.00(0.88-1.13)$ & & $0.96(0.85-1.09)$ & \\
\hline 2007 & 746 & 4.1 & $1.00(0.89-1.13)$ & & $0.97(0.86-1.10)$ & \\
\hline 2008 & 926 & 4.2 & $1.06(0.94-1.19)$ & $0.98(0.96-0.99)$ & $1.07(0.95-1.20)$ & $1.00(0.97-1.02)$ \\
\hline 2009 & 1387 & 5.6 & $0.95(0.85-1.06)$ & & $0.96(0.85-1.07)$ & \\
\hline 2010 & 1957 & 7.9 & $0.91(0.81-1.02)$ & & & \\
\hline
\end{tabular}

Group $3=$ PS 0/1/2 and stage IIIB

\begin{tabular}{|l|l|l|l|r|r|r}
\hline $2004 / 2005$ & 906 & 6 & 1 & 1 \\
2006 & 1034 & 6.7 & $0.97(0.89-1.06)$ & $0.96(0.87-1.05)$ & $0.97(0.88-1.05)$ \\
2007 & 1299 & 7.2 & $0.95(0.87-1.04)$ & $0.92(0.84-1.00)$ \\
2008 & 1789 & 8.2 & $0.90(0.83-0.98)$ & $0.99(0.97-1.00)$ \\
2009 & 2423 & 9.7 & $0.89(0.82-0.97)$ & $0.91(0.84-0.98)$ \\
2010 & 1909 & 7.7 & $0.89(0.82-0.98)$ & \\
\hline
\end{tabular}

Group $4=$ PS $3 / 4$ and stage IA-IIIA

\begin{tabular}{|l|l|l|l|l|}
\hline $2004 / 2005$ & 261 & 1.7 & 1 & \\
2006 & 211 & 1.3 & $1.16(0.96-1.40)$ & \\
2007 & 338 & 1.8 & $1.19(1.00-1.40)$ & \\
2008 & 481 & 2.2 & $1.10(0.94-1.28)$ & $0.98(0.95-1.01)$ \\
2009 & 745 & 3 & $1.04(0.89-1.21)$ & \\
2010 & 1077 & 4.3 & $1.17(1.01-1.35)$ & \\
\hline
\end{tabular}

Group $5=$ PS $0-4$, stage IV and PS $3 / 4$, stage IIIB

\begin{tabular}{|l|r|r|}
\hline $2004 / 2005$ & 2704 & 17.9 \\
2006 & 2995 & 19.4 \\
2007 & 4054 & 22.5 \\
2008 & 6054 & 27.9 \\
2009 & 8748 & 35.2 \\
2010 & 10129 & 41.1 \\
\hline \multicolumn{2}{|c|}{ Missing = either PS or stage missing } \\
\hline \multicolumn{2}{|c|}{$2004 / 2005$} \\
2006 & 9622 & 63.7 \\
2007 & 9317 & 60.4 \\
2008 & 10015 & 57.5 \\
2009 & 10362 & 47.8 \\
2010 & 8358 & 33.6 \\
\hline \multicolumn{2}{|c|}{}
\end{tabular}

Abbreviations: $\mathrm{Cl}=$ confidence interval; $\mathrm{HR}=$ hazard ratio; $\mathrm{PS}=$ performance status.

${ }^{a_{H}}$ azard ratios adjusted for sex, age, ethnicity, co-morbidity and source of referral.

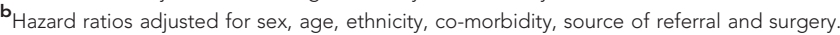

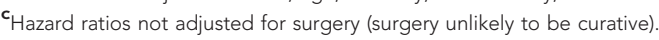

2006 (during which time only about $30 \%$ of the expected number of lung cancer cases were entered into the audit). In this analysis, there was still an annual improvement in survival (adjusted HR $0.98,95 \%$ CI $0.97-0.99$ ). In our database, the NLCA reported lower number of patients with surgical OPCS- 4 codes compared with the
HES database, and to avoid under-estimation, we used the HES database to identify patients who had surgery.

We included both people with histologically proven and people with presumed NSCLC in line with the NLCA definition. In case if the survival for these two groups was different, we analysed them 


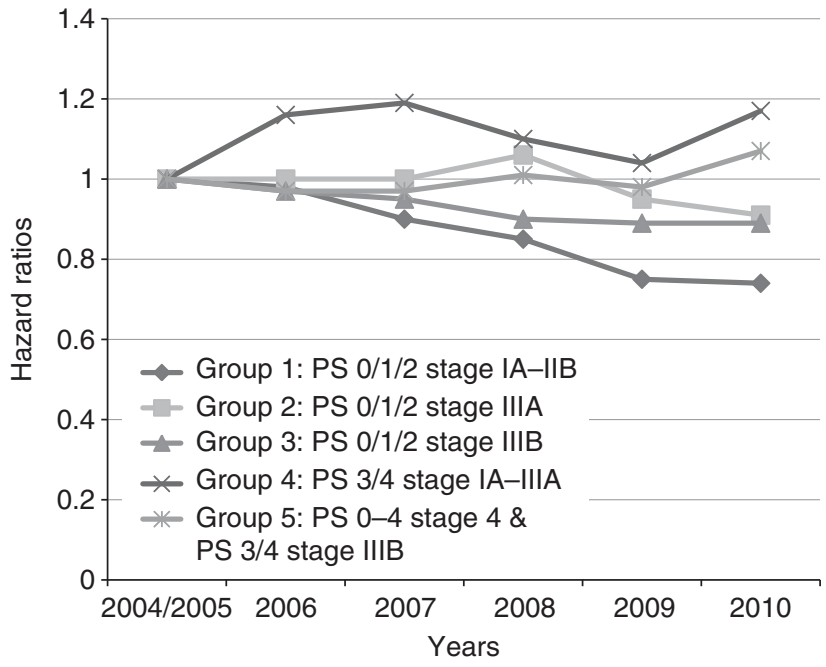

Figure 1. Variation in annual overall survival in NSCLC compared with 2004/2005. Hazard ratios adjusted for age, sex, co-morbidity, ethnicity and source of referral.

Table 4. Multivariate Cox regression analysis looking at the influence of surgery on overall survival since the introduction of the NLCA

\begin{tabular}{|c|c|c|c|}
\hline Year & $\begin{array}{l}\text { Total number } \\
\text { of patients }(n)\end{array}$ & $\begin{array}{c}\text { Proportion of } \\
\text { patients who } \\
\text { had surgery (\%) }\end{array}$ & $\begin{array}{c}\text { Adjusted } \\
\mathrm{HR}(95 \% \mathrm{Cl})^{\mathrm{a}}\end{array}$ \\
\hline \multicolumn{4}{|c|}{ Group $1=$ PS $0 / 1 / 2$ and stage IA-IIB } \\
\hline $\begin{array}{l}2004 / 2005 \\
2006 \\
2007 \\
2008 \\
2009\end{array}$ & $\begin{array}{l}1098 \\
1206 \\
1567 \\
2038 \\
3166\end{array}$ & $\begin{array}{l}49 \\
50 \\
54 \\
56 \\
57\end{array}$ & $\begin{array}{l}0.30(0.26-0.36) \\
0.34(0.29-0.40) \\
0.37(0.32-0.42) \\
0.32(0.28-0.37) \\
0.31(0.27-0.35)\end{array}$ \\
\hline \multicolumn{4}{|c|}{ Group $2=$ PS $0 / 1 / 2$ and stage IIIA } \\
\hline $\begin{array}{l}2004 / 2005 \\
2006 \\
2007 \\
2008 \\
2009\end{array}$ & $\begin{array}{r}496 \\
609 \\
746 \\
926 \\
1387\end{array}$ & $\begin{array}{l}18 \\
13.3 \\
15 \\
20 \\
18\end{array}$ & $\begin{array}{l}0.44(0.34-0.59) \\
0.39(0.30-0.52) \\
0.40(0.31-0.52) \\
0.46(0.37-0.56) \\
0.40(0.33-0.49)\end{array}$ \\
\hline $\begin{array}{l}\text { Abbreviation } \\
\text { HRs compare } \\
{ }^{\text {a Adjusted fo }}\end{array}$ & $\begin{array}{l}=\text { confidence int } \\
h \text { those who did } n \\
\text { age, PS, stage, et }\end{array}$ & ; HR=hazard ratio; & $\begin{array}{l}=\text { performance status } \\
\text { ar. } \\
\text { e of referral. }\end{array}$ \\
\hline
\end{tabular}

separately. Those with proven NSCLC were younger and with better PS compared with patients with presumed NSCLC (Supplementary Table 2), but the change in survival over time was almost identical to the whole cohort (Supplementary Table 3) when analysed by group.

As far as we are aware, this is the largest study which has looked at the change in overall survival based on the PS and stage in England. There are a few previous studies looking at age standardised to 5-year survival rates in England (ONS, 2011) and other European countries (Berglund et al, 2010); however, none of these divided the population according to prognostic features (e.g. PS and stage). We feel that this is important given the heterogeneity of patients with lung cancer.

Our study demonstrated that the improvement in overall survival is due to the improvement seen in patients with early stage disease and a good PS (groups 1 and 2). Increasing surgical resection rates seem to account for this survival benefit. However, it is likely that other factors may also be contributing, which were not adjusted for in this study. Not all patients with good PS and stage underwent surgery. The reason for this are unknown, however, it may be partly due to the patient choice or organisational factors such as whether a patient was first seen a surgical trust.

We were unable to account for the remaining survival advantage seen in group 1. Over the time period there has been a better subtyping of NSCLC, but this did not influence survival or explain the survival advantage in group 1 . We suggest that NHS trust level factors such as increasing numbers of thoracic surgeons (Lau et al, 2013), better imaging facilities and reduced time on the lung cancer diagnostic pathway are likely to be relevant. In addition, new radiotherapy techniques have become available and much more detailed radiotherapy data will be combined with the NLCA data in upcoming years, giving us the opportunity to assess this further.

Comparison with other studies. A few studies have looked at PS and stage as being the 'best prognostic factor' in clinical practice and found influences on overall survival to be similar to our results (Capewell and Sudlow, 1990; Patel and Shrager, 2005; Berghmans, 2011). A study done by the Edinburgh lung cancer group prospectively registered 651 patients with lung cancer from 1981 and found that survival was highest in patients selected for surgery and with good PS and early-stage disease (Capewell and Sudlow, 1990).

Using the NLCA database, we were able to show a rise in resection rates in England similar to other studies which have used the Cancer Repository data sets (Page et al, 2011; Riaz et al, 2012a). We were also able to show that the increase in surgical resection rates corresponded with better survival rates which is similar to a population study $(n=77349)$ using the National Cancer Data Repository in England (Riaz et al, 2012b). They used data from 2004 to 2006, which revealed that a higher surgical resection rate was strongly associated with better survival (HR 0.88, 95\% CI 0.86-0.91 in highest resected quintile compared with lowest resected quintile). Another study using Norwegian cancer registry data from 1993 to 2002 looked at 3211 patients who had a surgical resection and showed long-term survival benefits among these patients (Strand et al, 2006). The results are comparable to ours which suggest some survival benefits (especially for patients with good PS and early stage) when adjusted for surgery. Although other studies have found the likelihood of having surgery to be confounded by age, socioeconomic status (SES) and co-morbidity (Strand et al, 2006; Riaz et al, 2012b), our study is more comprehensive and relevant as it looks at the features which most strongly influence the likelihood of having surgery, that is, stage and PS while adjusting for other prognostic features.

The ONS data showed an improvement in survival for all lung cancer from 1996 to 2009 (ONS, 13th December 2011). The net 1 -year survival improved from $21.1 \%$ to $28.8 \%$ for males and from $22.6 \%$ to $32.1 \%$ for female. However, these results do not take into considerations any patient features other than age and sex. We believe our results are more comprehensive as they take into account the PS and stage (which have been found to strongly influence survival) and also treatment (i.e. surgery). We were unable to adjust for SES while calculating the overall survival owing to the high level of missing data at the beginning of the NLCA. However, when we adjusted for SES for years which have more complete data (2007-2010), it made no difference to overall survival which was consistent with other studies (Crawford et al, 2009; Rich et al, 2011a,b) (data not shown).

Clinical relevance. The overall survival of patients with lung cancer has changed very little since the NLCA was initiated in 2004 , with just a $1 \%$ annual improvement. However, by stratifying 
Table 5. Survival analysis by stratified group adjusted for patient features and histology ( $n=28997)$

\begin{tabular}{|c|c|c|c|c|c|}
\hline Years & $\begin{array}{l}\text { Number of } \\
\text { patients }(n)\end{array}$ & $\begin{array}{c}\text { Proportion of } \\
\text { adenocarcinomas (\%) }\end{array}$ & $\operatorname{HR}(95 \% \mathrm{Cl})^{\mathrm{a}}$ & Annual HR $(95 \% \mathrm{Cl})^{\mathrm{a}}$ & $\operatorname{HR}(95 \% \mathrm{Cl})^{\mathrm{b}}$ \\
\hline \multicolumn{6}{|c|}{ Group $1=$ PS $0 / 1 / 2$ and stage IA-IIB } \\
\hline $2004 / 2005$ & 625 & 38.5 & 1 & & 1 \\
\hline 2006 & 600 & 39.8 & $0.99(0.86-1.14)$ & & $0.99(0.86-1.14)$ \\
\hline 2007 & 884 & 42 & $0.93(0.81-1.06)$ & & $0.93(0.82-1.06)$ \\
\hline 2008 & 1148 & 46.9 & $0.85(0.75-0.97)$ & $0.96(0.94-0.99)$ & $0.86(0.76-0.98)$ \\
\hline 2009 & 1865 & 49 & $0.71(0.63-0.81)$ & & $0.72(0.64-0.82)$ \\
\hline 2010 & 2256 & 52.2 & $0.72(0.63-0.83)$ & & $0.74(0.65-0.85)$ \\
\hline
\end{tabular}

Group 2 = PS $0 / 1 / 2$ and stage IIIA

\begin{tabular}{|l|r|r}
\hline $2004 / 2005$ & 263 & 34.6 \\
2006 & 266 & 29.7 \\
2007 & 354 & 33.3 \\
2008 & 486 & 34.1 \\
2009 & 731 & 35.2 \\
2010 & 1159 & 39.8
\end{tabular}

\begin{tabular}{c|c|c}
1 & & 1 \\
$0.98(0.82-1.18)$ & & $0.97(0.81-1.17)$ \\
$1.03(0.87-1.22)$ & $0.98(0.95-1.00)$ & $1.02(0.86-1.22)$ \\
$1.01(0.86-1.20)$ & & $1.01(0.86-1.19)$ \\
$0.92(0.79-1.08)$ & & $0.92(0.79-1.08)$ \\
$0.90(0.77-1.05)$ & & $0.90(0.77-1.05)$
\end{tabular}

Group $3=$ PS 0/1/2 and stage IIIB

\begin{tabular}{|l|r|l}
\hline $2004 / 2005$ & 464 & 33.8 \\
2006 & 476 & 36.7 \\
2007 & 615 & 36 \\
2008 & 833 & 39.3 \\
2009 & 1188 & 34.6 \\
2010 & 1063 & 34.9
\end{tabular}

\begin{tabular}{c|}
1 \\
$0.98(0.86-1.12)$ \\
$0.95(0.84-1.08)$ \\
$0.86(0.77-0.97)$ \\
$0.87(0.78-0.98)$ \\
$0.90(0.79-1.01)$
\end{tabular}

$0.98(0.86-1.12)$ $0.95(0.84-1.08)$ $0.86(0.77-0.97)$ $0.87(0.78-0.98)$ $0.90(0.79-1.01)$

Group $4=$ PS $3 / 4$ and stage IA-IIIA

\begin{tabular}{|l|r|r|}
\hline $2004 / 2005$ & 59 & 15.2 \\
2006 & 49 & 24.4 \\
2007 & 74 & 33.7 \\
2008 & 113 & 24.7 \\
2009 & 152 & 32.2 \\
2010 & 224 & 22.3 \\
\hline
\end{tabular}

\begin{tabular}{c|}
1 \\
$1.13(0.75-1.69)$ \\
$1.08(0.75-1.56)$ \\
$1.06(0.75-1.48)$ \\
$0.99(0.71-1.37)$ \\
$1.20(0.88-1.65)$
\end{tabular}

$1.00(0.94-1.06)$

$1.13(0.75-1.68)$

$1.09(0.75-1.57)$

$1.05(0.75-1.48)$

$0.99(0.71-1.38)$

$1.20(0.88-1.65)$

$0.96(0.94-0.99)$

Group $5=$ PS 0-4, stage IV and PS $3 / 4$ stage IIIB

\begin{tabular}{|l|l|l|l|l|l|}
\hline $2004 / 2005$ & 1060 & 52.8 & 1 & 1 \\
2006 & 1036 & 51.4 & $1.02(0.93-1.11)$ & $1.02(0.93-1.11)$ \\
2007 & 1449 & 54.7 & $1.01(0.93-1.09)$ & $0.99(0.98-1.01)$ & $1.01(0.93-1.09)$ \\
2008 & 2094 & 56.3 & $1.06(0.99-1.15)$ & $1.00(0.98-1.01)$ & $1.07(0.99-1.15)$ \\
2009 & 3196 & 60.9 & $1.00(0.93-1.07)$ & $1.05(0.93-1.08)$ \\
2010 & 4215 & 62.4 & $1.05(0.97-1.12)$ & \\
\hline
\end{tabular}

Abbreviations: $\mathrm{Cl}=$ confidence interval; $\mathrm{HR}=$ hazard ratio; $\mathrm{PS}=$ performance status.

${ }^{a}$ Hazard ratios adjusted for sex, age, ethnicity, co-morbidity and source of referral.

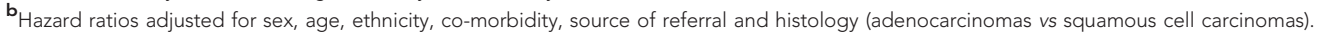

patients according to the PS and stage, we were able to identify an improvement in survival for patients with good PS and early-stage disease and to demonstrate that this is partly explained by the increasing surgical resection rates. Unfortunately, the majority of patients present with metastatic disease and these people strongly influence the overall survival of patients with lung cancer. Therefore, we would suggest that screening programmes, public awareness campaigns and other interventions, which increase the proportion of patients detected at an early stage, who are then suitable for surgical resection, are absolutely key to improving survival for people with lung cancer in England.

Authorship. The conception of the study was done by RBH, ALR and RAS. AK acquired the data from the Health and Social Care Information Centre (HSCIC) and all analysis was done by AK. $\mathrm{RBH}$ and ALR were involved in the data interpretation. Majority of the paper (including the initial draft) was written by AK, and HAP. LJT, RAS, JPD, DRB, ALR and RBH were involved revising the paper critically. This final manuscript was approved by all the authors prior to submission.

Ethics. This study uses data which is collected as a part of NHS audit. The data sharing agreement were obtained to use the linked audit data from the HSCIC.

\section{ACKNOWLEDGEMENTS}

We would like to acknowledge the British Lung Foundation who funded AK and RBH, and the HSCIC (Arthur Yelland and Xanthe Hannah), who provided data. We would also like to thank the wider NLCA steering group (Professor Anne Tattersfield, Dr Catherine Free, Dr Laura Jones, Dr Michael Peake and Dr Paul Beckett). 


\section{CONFLICT OF INTEREST}

ALR, DRB, JPD and HAP have no conflict of interest. LJT has conducted the statistical analyses for the National Lung Cancer Audit annual reports for the past 4 years, which was funded by the NHS Information Centre; LJT has not received any personal earnings from the HSCIC for this work. RBH has a grant provided by the British Lung Foundation chair of respiratory epidemiology and has a minor consultancy role with GSK concerning the people with lung fibrosis where he was paid $£ 350$. He was also a coapplicant on a grant for $£ 500000$ from GSK to look at biomarkers for lung fibrosis. RAS is employed by the NHS Health and Social Care Information Centre as the Project Manager for the NLCA. $\mathrm{AK}$ is also doing his $\mathrm{PhD}$ from University of Nottingham on a studentship provided by the British Lung Foundation.

\section{REFERENCES}

Berghmans T (2011) Prognostic factors in stage III non-small cell lung cancer: a review of conventional, metabolic and new biological variables. Ther $A d v$ Med Oncol 3: 127-138.

Berglund A, Holmberg L, Tishelman C, Wagenius G, Eaker S, Lambe M (2010) Social inequalities in non-small cell lung cancer management and survival: a population-based study in central Sweden. Thorax 65: 327-333.

Campbell SE, Campbell MK, Grimshaw JM, Walker AE (2001) A systematic review of discharge coding accuracy. J Public Health Med 23: 205-211.

Capewell S, Sudlow MF (1990) Performance and prognosis in patients with lung cancer. The Edinburgh Lung Cancer Group. Thorax 45: 951-956.

Coleman MP, Forman D, Bryant H, Butler J, Rachet B, Maringe C, Nur U, Tracey E, Coory M, Hatcher J, Mcgahan CE, Turner D, Marrett L, Gjerstorff ML, Johannesen TB, Adolfsson J, Lambe M, Lawrence G, Meechan D, Morris EJ, Middleton R, Steward J, Richards MA. Group, IMW (2011) Cancer survival in Australia, Canada, Denmark, Norway, Sweden, and the UK, 1995-2007 (the International Cancer Benchmarking Partnership): an analysis of population-based cancer registry data. Lancet 377: $127-138$.

Coleman MP, Quaresma M, Berrino F, Lutz J-M, De Angelis R, Capocaccia R, Baili P, Rachet B, Gatta G, Hakulinen T, Micheli A, Sant M, Weir HK, Elwood JM, Tsukuma H, Koifman S, E Silva GA, Francisci S, Santaquilani M, Verdecchia A, Storm HH, Young JL. Group, CW (2008) Cancer survival in five continents: a worldwide population-based study (CONCORD). Lancet Oncol 9: 730-756.

Crawford SM, Sauerzapf V, Haynes R, Zhao H, Forman D, Jones AP (2009) Social and geographical factors affecting access to treatment of lung cancer. Br J Cancer 101: 897-901.

Imperatori A, Harrison RN, Leitch DN, Rovera F, Lepore G, Dionigi G, Sutton P, Dominioni L (2006) Lung cancer in Teesside (UK) and Varese (Italy): a comparison of management and survival. Thorax 61: 232-239.
Lau KKW, Rathinam S, Waller DA, Peake MD (2013) The effects of increased provision of thoracic surgical specialists on the variation in lung cancer resection rate in England. J Thorac Oncol 8: 68-72.

NHSIC (2010) National Lung Cancer Audit 2010 [Online].

NHSIC (2011) National Lung Cancer Audit Report 2011 [Online]. Available http://www.hqip.org.uk/assets/NCAPOP-Library/Lung-Cancer-NHS-ICAUDIT-2011.pdf.

Nice. April (2011) Lung Cancer: The diagnosis and treatment of lung cancer [Online]. Available http://www.nice.org.uk/nicemedia/live/13465/54202/ 54202.pdf.

ONS (2011) Cancer Survival by Cancer Network in England - Patients diagnosed 1996-2009 and followed up to 2010 [Online]. England. Available http://www.ons.gov.uk/ons/dcp171778_247385.pdf [Accessed 13 December 2011].

ONS (2011) Cancer Survival in England - Patients Diagnosed 2005-2009 and Followed up to 2010 [Online]. Office of National Statistics. Available at http://www.ons.gov.uk/ons/rel/cancer-unit/cancer-survival/2005-2009followed-up-to-2010/summary-cancer-survival-2005-2009-followed-upto-2010.html.

Page RD, Mcshane J, Kinsman R (2011) Second National Thoracic Surgery Activity \& Outcomes Report 2011. Henley-on-Thames: Society of Cardiothoracic Surgery in Great Britain \& Ireland.

Patel V, Shrager JB (2005) Which patients with stage III non-small cell lung cancer should undergo surgical resection? Oncologist 10: 335-344.

Powell HA, Tata LJ, Baldwin DR, Stanley RA, Khakwani A, Hubbard RB (2013) Early mortality after surgical resection for lung cancer: an analysis of the English National Lung cancer audit. Thorax 68(9): 826-834.

Riaz SP, Linklater KM, Page R, Peake MD, Moller H, Luchtenborg M (2012a) Recent trends in resection rates among non-small cell lung cancer patients in England. Thorax 67: 811-814.

Riaz SP, Luchtenborg M, Jack RH, Coupland VH, Linklater KM, Peake MD, Moller H (2012b) Variation in surgical resection for lung cancer in relation to survival: population-based study in England 2004-2006. Eur J Cancer 48: 54-60.

Rich AL, Tata LJ, Free CM, Stanley RA, Peake MD, Baldwin DR, Hubbard RB (2011a) Inequalities in outcomes for non-small cell lung cancer: the influence of clinical characteristics and features of the local lung cancer service. Thorax 66: 1078-1084.

Rich AL, Tata LJ, Stanley RA, Free CM, Peake MD, Baldwin DR, Hubbard RB (2011b) Lung cancer in England: information from the National Lung Cancer Audit (LUCADA). Lung Cancer 72: 16-22.

Strand TE, Rostad H, Moller B, Norstein J (2006) Survival after resection for primary lung cancer: a population based study of 3211 resected patients. Thorax 61: 710-715.

Woolhouse I (2011) Variation in lung cancer outcomes in the UK and Europe. Clin Med 11: 110-111.

This work is published under the standard license to publish agreement. After 12 months the work will become freely available and the license terms will switch to a Creative Commons AttributionNonCommercial-Share Alike 3.0 Unported License.

Supplementary Information accompanies this paper on British Journal of Cancer website (http://www.nature.com/bjc) 